\title{
Theoretical Verification Necessity of Leakage Currents Using Sm Doped Ceria Electrolytes in SOFCs
}

\author{
T. Miyashita*
}

1-6-3, Mitsuya-kita, Yodogawa-ku, Osaka, Japan 532-0032

\begin{abstract}
Numerous approaches have been made to solve the basic transport equation that describes a solid oxide fuel cell (SOFC) with mixed conduction. Classically, the open circuit voltage (OCV) is calculated with Wagner's equation, which is right within the limits of linear transport theory. In order to generalize Wagner's equation, many models have been proposed to describe the current-voltage relation in mixed ionic electronic solid conductors (MIEC) using constant field approximation to calculate an electronic current. However, experimental verification necessity of leakage currents in SOFCs using Sm doped Ceria electrolytes has already been pointed out both qualitatively and in quantities. Using the constant field approximation, the limits of linear transport theory can not be clear. In this report, a new model is expressed without using the constant field approximation. This model follows from Wagner's equation and continuity. The calculated electronic current for doped Ceria electrolyte matches the values calculated using conventional models. But the electrical field near the cathode is large enough to cause dielectric breakdown which has never been reported. Continuity is not deniable, so there are limitations in Wagner's equation, coming from the limits of linear transport theory.
\end{abstract}

Keywords: SOFC, Ceria, Wagner's equation, Constant field approximation, Riess's model.

\section{INTRODUCTION}

The Nernst voltage $(\mathrm{V}$ th) is expressed as:

$V_{t h}=\frac{R T}{4 F} \ln \left(\frac{p O_{2}^{\prime}}{p O_{2}^{\prime \prime}}\right)$

where $\mathrm{R}$ is the gas constant and $\mathrm{T}$ is the absolute temperature in Kelvin. $\mathrm{F}$ is the Faraday's constant. $p O_{2}^{\prime}$ and $p O_{2}^{\prime \prime}$ are the oxygen partial pressures at cathode and anode, respectively. With mixed conducting electrolytes, there are ionic (Ii) and electronic currents (Ie), even in the absence of an external current. When tion (ionic transference number) is constant,

$$
\begin{aligned}
& I_{i}=\frac{V_{t h}-O C V}{R_{i}} \\
& I_{e}=-\frac{O C V}{R_{e}}
\end{aligned}
$$

where $\mathrm{Ri}$ and $\mathrm{Re}$ are ionic resistance and electronic resistance of the electrolyte, respectively. Here, the sum of Ii and Ie is zero. Thus,

$$
O C V=\frac{R_{e}}{R_{i}+R_{e}} V_{t h}
$$

Wagner's equation is expressed as [1]:

*Address correspondence to this author at the 11-6-3, Mitsuya-kita, Yodogawa-ku, Osaka, Japan 532-0032; Tel: 090-1204-1259;

Fax: +81-797-32-6171; E-mail: tom_miya@ballade.plala.or.jp

$$
\begin{aligned}
& t_{\text {ion }}=\frac{R_{e}}{R_{i}+R_{e}} \\
& O C V=t_{\text {ion }} \times \frac{R T}{4 F} \ln \left(\frac{p O_{2}^{\prime}}{p O_{2}^{\prime \prime}}\right)
\end{aligned}
$$

In Equation 6, the constant field approximation in equation 6 is justified because $\mathrm{Ri}$ and $\mathrm{Re}$ are constant When tion is not constant in the electrolyte, Wagner's equation is expressed as [1]:

$$
O C V=\frac{1}{4 F} \int_{\mu O_{2}^{\prime}}^{\mu O_{2}^{\prime \prime}} t_{i o n} d \mu O_{2}
$$

where $\mu^{\prime} O_{2}$ and $\mu^{\prime \prime} O_{2}$ are the chemical potentials of oxygen on the cathode and anode side of the electrolyte, respectively. The oxygen chemical potential given by,

$$
\mu O_{2}=\mu O_{2}^{0}+R T \ln \left(\frac{p O_{2}}{p O_{2}^{0}}\right)
$$

where $\mu O_{2}^{0}$ and $p O_{2}^{0}$ are the standard oxygen chemical potential and the standard oxygen pressure, respectively. Thus, combining equations 7 and 8 gives [2],

$O C V=\frac{R T}{4 F} \int_{p O_{2}^{\prime}}^{p O_{2}^{\prime \prime}} t_{i o n} d \ln p O_{2}$

When tion is constant in the electrolyte, Equation 9 and Equation 6 are identical. Equation 9 is a classical equation that is still used for modern theoretical calculations [3], which is right within the limits of linear transport theory. 
The generalized form of equation 9 allows for Ie to be calculated from the constant field approximation [4].

However, experimental verification necessity of leakage currents using Sm doped Ceria electrolytes in SOFCs was already made sure qualitatively [5] and in quantities [6].

\section{CURRENT-VOLTAGE RELATION IN MIXED IONIC ELECTRONIC SOLID CONDUCTORS}

In order to calculate the current-voltage relation in MIEC, we consider the following:

$I_{e}=-k \times I_{i}$

where $\mathrm{k}$ is constant in the electrolyte, from Equation 2 and Equation 3,

$$
\begin{aligned}
& I_{i}=\frac{V_{t h}-V_{\text {cell }}}{R_{i}} \\
& I_{e}=-\frac{V_{\text {cell }}}{R_{e}} \\
& I_{\text {ext }}=I_{i}+I_{e}=(1-k) \times I i=(1-k) \times \frac{V_{t h}-V_{c e l l}}{R_{i}}
\end{aligned}
$$

where Vcell and Iext are the cell voltage and output current, respectively. From Equations 10, 11 and12,

$V_{\text {cell }}=\frac{k \times R_{e}}{R_{i}+k R_{e}} V_{t h}$

$f(k)=\frac{k \times R_{e}}{R_{i}+k \times R_{e}}=\frac{k \times t_{i o n}}{(k-1) \times t_{i o n}+1}$

where $f(k)$ is solely a function of $k$. If tion is not constant for the electrolytes, then $f(k)$ is not constant. Under these conditions, the electrolyte is treated as a collection of series meshes. The voltage is calculated by summing the voltages for each mesh, given their local oxygen pressure in the electrolyte. This scenario is graphically depicted in Fig. (1). In Fig. (1), Considering continuity, Ii and Ie should be same value in every mesh. Equation 14 and Equation 15 are applied for each mesh, therefore,

$$
V_{\text {cell }}=\frac{R T}{4 F} \int_{p_{O^{\prime} 2}}^{p^{O^{\prime \prime}} 2} f(k) d \ln p O_{2}
$$

Equation 16 is a generalized version of Wagner's equation. When $\mathrm{k}$ equals to $1, \mathrm{~V}$ cell equals to $\mathrm{OCV}$, so Equation 16 and Equation 9 are identical. For doped Ceria electrolytes, tion is expressed as [3]:

$$
t_{i o n}=\frac{1}{1+\left(\frac{p O_{2}}{p O_{2}^{*}}\right)^{-\frac{1}{4}}}
$$

where $p O_{2}^{*}$ corresponds to an oxygen partial pressure at which the ionic transference number is 0.5 . Unfortunately,
Equation 16 and 17 cannot be integrated mathematically, and must be solved numerically. By continuity, the thickness of each mesh is:

$l_{\text {mesh }}=l_{\text {average }}\left(\frac{1-f_{\text {mesh }}(k)}{1-f_{\text {average }}(k)}\right)$

where faverage $(\mathrm{k})$ comes from Equation 14 and laverage is the calculated thickness of the mesh using faverage $(\mathrm{k})$. fmesh $(\mathrm{k})$ and lmesh represent $f(k)$ and actual mesh thickness, respectively. A mathematical proof for Equation 18 is given in Appendix 1. Equation 18 shows that the oxygen partial pressure in the electrolyte is determined by continuity and Wagner's equation.

Calculations were done using 500 mesh elements in Microsoft Excel, without a numerical solver. The temperature was $873 \mathrm{~K}$. $100 \%$ Oxygen gas (1atm) was fed to the cathode, and hydrogen gas with $3 \%$ steam was supplied to the anode as the fuel gas $\left(8.3 \times 10^{-28} \mathrm{~atm}\right)$. At $873 \mathrm{~K}, \quad p O_{2}^{*}$ is $2 \times 10^{-25} \mathrm{~atm}$ [6]. The Ri was $1 \mathrm{ohm}$. Conductivity is 0.02 $\mathrm{S} / \mathrm{cm}$. Using $1 \mathrm{~cm}^{2}$ electrodes, thickness is $0.02 \mathrm{~cm}(=0.02 / 1)$. A 30 meshes calculation example is shown in Appendix 2.

$\mathrm{V}$ th is $1.174 \mathrm{~V}$. When $\mathrm{k}$ is 1 , tion is 0.898 . The corresponding OCV is $1.054 \mathrm{~V}(=1.174 \mathrm{~V} \times 0.898)$, which also agrees with previous work [7]. The calculations for the relationship between tion and $\log (\mathrm{pO} 2)$ are shown in Fig. (2). These results agree with previous reports [6].

The ionic current-voltage relation, electronic current-voltage relation, external current-voltage relation and external current-power output relation are shown in Figs. (3-6), respectively.

From Riess's model [4], Ie is;

$I_{e}=\frac{V_{t h}-V}{R_{e_{-} \text {cathode }}} \times \frac{e^{-\beta q(V t h-V)}-e^{-\beta q V t h}}{1-e^{-\beta q(V t h-V)}}$

where $\beta, q$ and Re_cathode are the reciprocal of the multiplication of Boltzmann constant and absolute temperature, elementary charge and electronic resistance near the cathode. The Re_cathode was $3.94 \mathrm{ohm}$ at OCV condition. This value is much less than the resistance of air, $1.3 \mathrm{M} \mathrm{ohm}$, when $\mathrm{Ri}$ is $1 \mathrm{ohm}$, which has been explained by the high mobility of electrons. The calculated electronic current matches the values predicted by Reiss' model. Theoretical explanation is shown in Appendix 3.

The calculated relationship between the distance from the cathode and voltage, $\log (\mathrm{pO} 2), \log ($ electrical field) are shown in Figs. (7-9), respectively. As seen in Figs. $(\mathbf{7}, \mathbf{8})$, in the absence of a large external current, voltage and log (pO2) change abruptly near the cathode. Without large external currents, large voltage losses are observed in the $0.02 \%$ thickness of electrolytes near the cathode. With $0.02 \mathrm{~cm}$ thick electrolytes, this distance is $40 \mathrm{~nm}$. The lattice constant is $0.54 \mathrm{~nm}$, which means that there are only 74 lattices within the $40 \mathrm{~nm}$ distance. Therefore, the constant field approximation cannot be used in this case. As seen in Fig. (9), a problem is discovered in our calculation. Even for an electrolyte $0.02 \mathrm{~cm}$ thick, the electrical field near the cathode 
is greater than $880 \mathrm{MV} / \mathrm{m}$. This value is large enough to cause dielectric breakdown which has never been reported.

Consequently, continuity is not deniable, so there are limitations in Wagner's equation, coming from the limits of linear transport theory. Leakage currents in SOFCs using doped Ceria electrolytes must be completely verified theoretically.

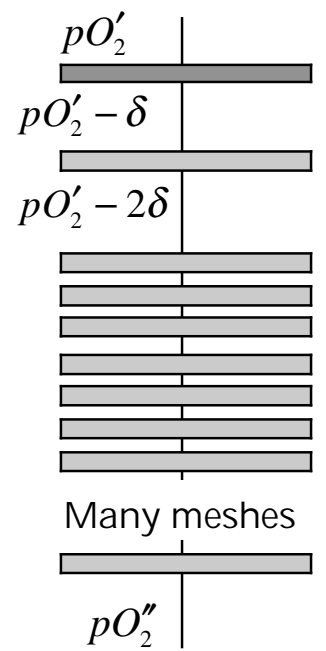

Fig. (1). Graphical depiction of Eq. 16. Considering continuity, Ii and Ie should be same value in every mesh. Equation 14 and Equation 15 are applied for each mesh.

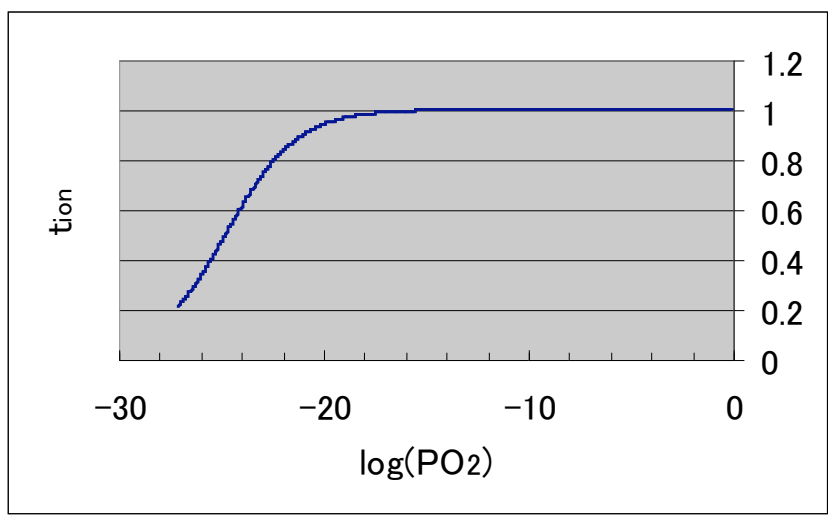

Fig. (2). Relationship between $\log \left(\mathrm{pO}_{2}\right)$ and tion. These results agree with previously reported experimental results.

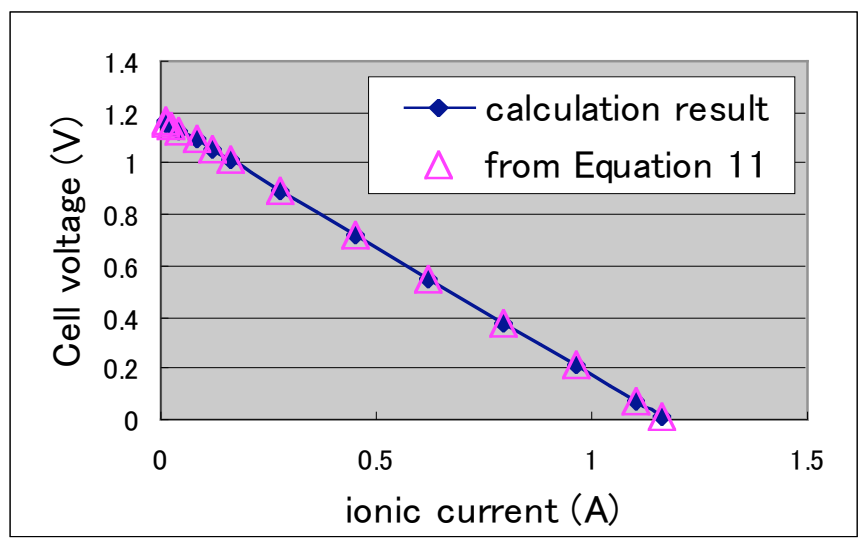

Fig. (3). Ionic current-voltage relation. The calculation results agree with Eq. 11.

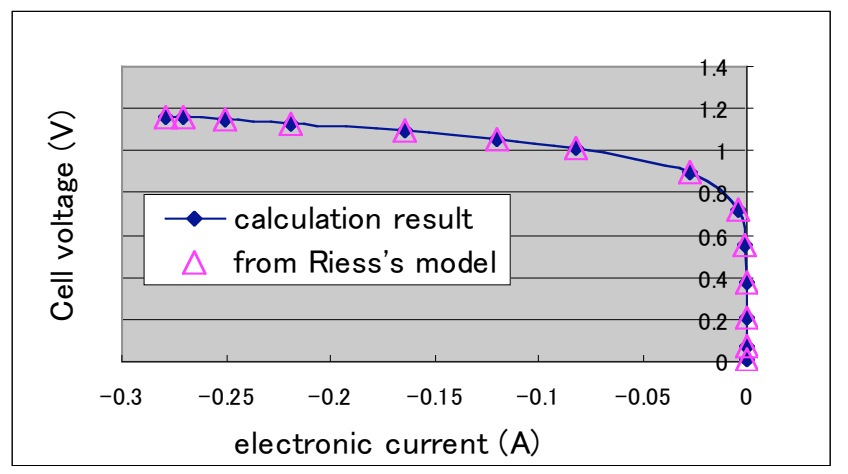

Fig. (4). Electronic current-voltage relation. The calculated electronic current matches the values predicted by Reiss' model.

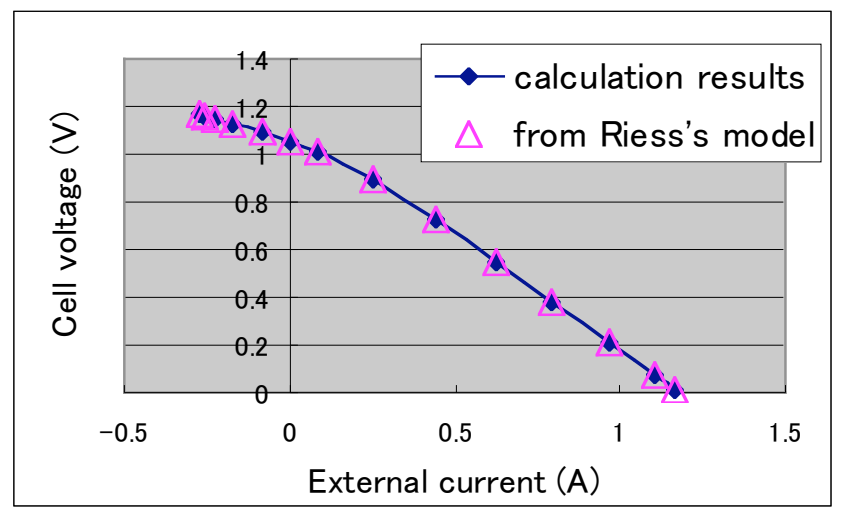

Fig. (5). External current-voltage relation. The calculated external current matches the values predicted by Reiss' model.

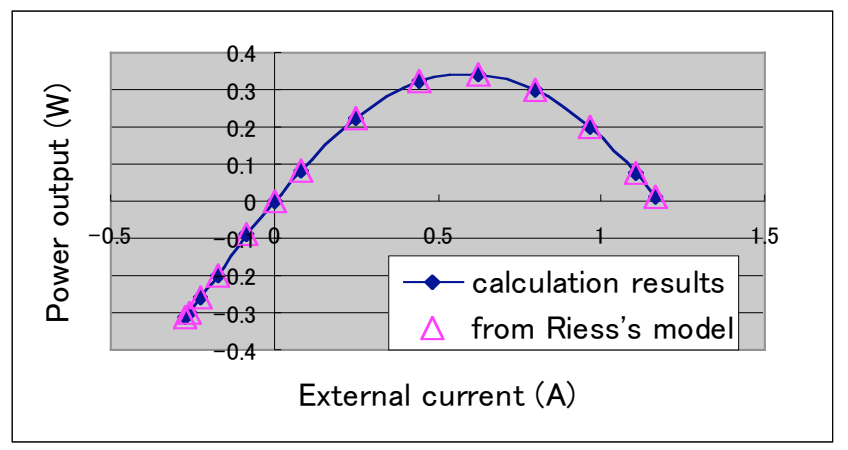

Fig. (6). External current-power output relation. The calculated power output matches the values predicted by Reiss' model.

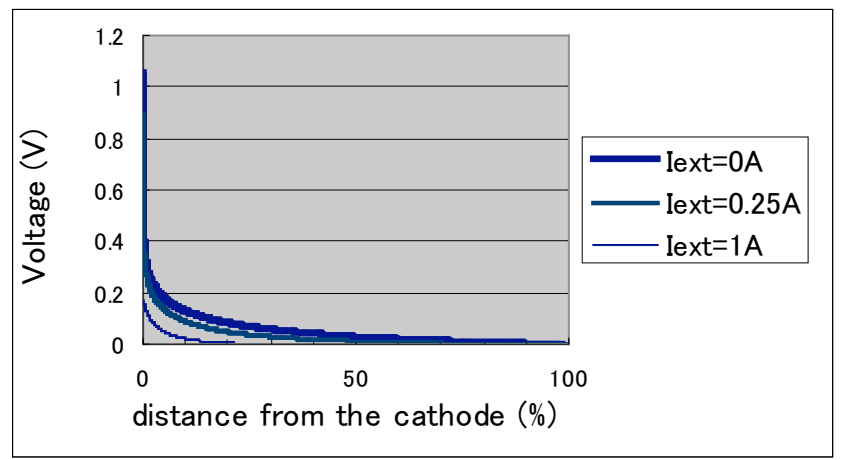

Fig. (7). Relationship between distance from the cathode and voltage. Without large external current, voltage abruptly changes near the cathode. 


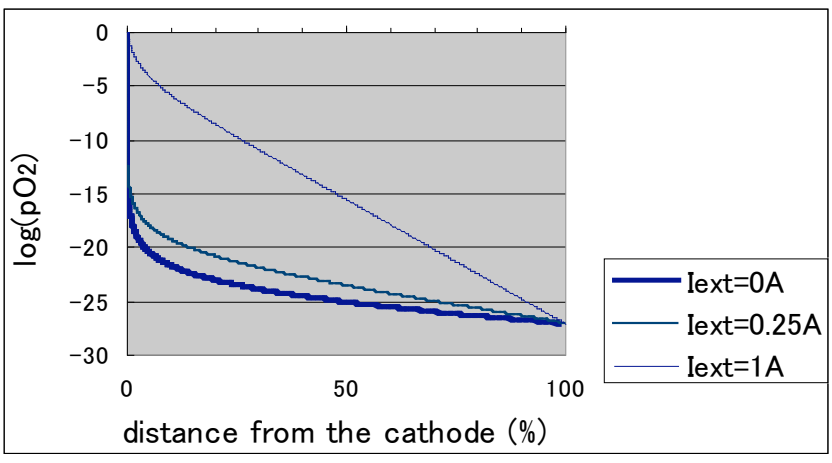

Fig. (8). Relationship between the distance from the cathode and $\log \left(\mathrm{pO}_{2}\right)$. Without large external current, $\log \left(\mathrm{pO}_{2}\right)$ abruptly changes near the cathode.

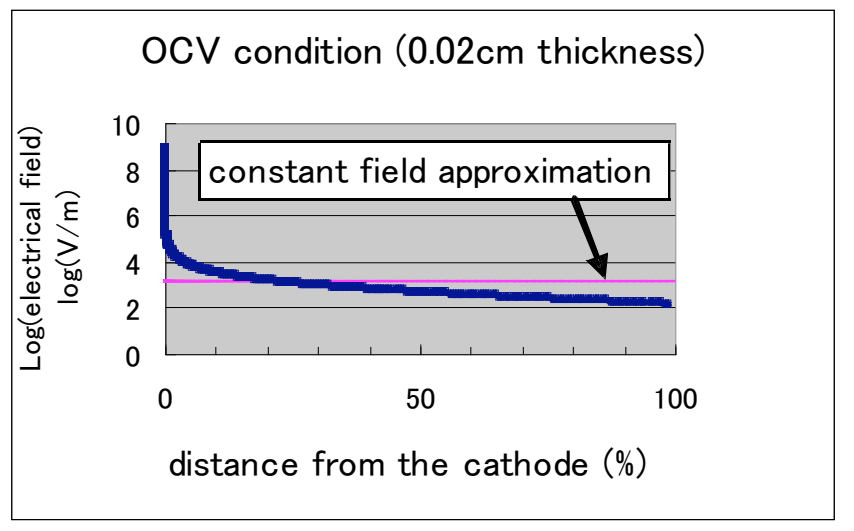

Fig. (9). Relationship between the distance from the cathode and $\log$ (electrical field). Even for an electrolyte $0.02 \mathrm{~cm}$ thick, the electrical field near the cathode is greater than $880 \mathrm{MV} / \mathrm{m}$.

\section{SUMMARY}

Numerous approaches have been made to solve the basic transport equation that describes SOFCs with mixed conduction. Classically, OCV is calculated with Wagner's equation, which is right within the limits of linear transport theory. In order to generalize Wagner's equation, many models have been proposed to describe the current-voltage relation in MIEC using constant field approximation to calculate an electronic current. Experimental verification necessity of leakage currents in SOFCs using Sm doped Ceria electrolytes has already been pointed out both qualitatively and in quantities. But these experimental results were ignored by the reason of no theoretical descriptions for the necessity. Using the constant field approximation, the limits of linear transport theory cannot be clear.

In this report, a new model is expressed without using the constant field approximation. This model follows from Wagner's equation and continuity. The calculated electronic current for doped Ceria electrolyte matches the values calculated using conventional models.

But the constant field approximation cannot be used in this case. Without large external currents, large voltage losses are observed in the $0.02 \%$ thickness of electrolytes near the cathode. With $0.02 \mathrm{~cm}$ thick electrolytes, this distance is $40 \mathrm{~nm}$. The lattice constant is $0.54 \mathrm{~nm}$, which means that there are only 74 lattices within the $40 \mathrm{~nm}$ distance. Furthermore, the electrical field near the cathode is large enough to cause dielectric breakdown which has never been reported.

Continuity is not deniable, so there are limitations in Wagner's equation, coming from the limits of linear transport theory. Leakage currents in SOFCs using doped Ceria electrolytes must be completely verified theoretically.

\section{APPENDIX 1}

A mathematical proof for Equation 18 is given in this appendix.

Table 1. Symbol List

\begin{tabular}{|c|c|c|}
\hline Symbol & Explanation & Status \\
\hline $\mathrm{N}$ & the number of meshes & constant \\
\hline$p O_{2}^{\prime}$ & Oxygen partial pressures at the cathode & constant \\
\hline$p O_{2}^{\prime \prime}$ & Oxygen partial pressures at the anode & constant \\
\hline$V_{\text {th }}$ & Nernst voltage of the cell & determined \\
\hline $\mathrm{V}_{\text {cell }}$ & the cell voltage & variable of cell \\
\hline Vth_mesh & Nernst voltage of mesh & determined \\
\hline$V_{\text {mesh }}$ & the voltage across each mesh & variable of mesh \\
\hline faverage $(\mathrm{k})$ & $\mathrm{V}_{\text {cell }} / \mathrm{V}_{\text {th }}$ & variable of cell \\
\hline fmesh $(k)$ & Vmesh/Vth_mesh & variable of mesh \\
\hline $\mathrm{L}$ & thickness of the electrolyte & constant \\
\hline lmesh & thickness of the mesh & variable of mesh \\
\hline laverage & thickness of mesh when $\mathrm{fmesh}(\mathrm{k})$ is equal to faverage $(\mathrm{k})$ & determined \\
\hline $\mathrm{Ri}$ & ionic resistance of the electrolyte & constant \\
\hline $\mathrm{ri}$ & ionic resistance of the mesh & variable of mesh \\
\hline
\end{tabular}


$V_{\text {cell }}=f_{\text {average }}(k) \times V_{\text {th }}$

The difference in $\ln (\mathrm{pO} 2)$ between cathode and anode side of mesh is $\frac{\ln \left(p O_{2}^{\prime}\right)-\ln \left(p O_{2}^{\prime \prime}\right)}{N}$.

$l_{\text {average }}=\frac{L}{N}$

$V_{t h \_m e s h}=\frac{V_{t h}}{N}$

$V_{\text {cell }}=\sum_{1}^{N} V_{\text {mesh }}=\sum_{1}^{N}\left(f_{\text {mesh }}(k) \times V_{\text {th_mesh }}\right)=\frac{V_{\text {th }}}{N} \sum_{1}^{N} f_{\text {mesh }}(k)$

Thus, from Equation 20 and Equation 23,

$\frac{1}{N} \sum_{1}^{N} f_{\text {mesh }}(k)=f_{\text {average }}(k)$

From Equation 18,

$\sum_{1}^{N} l_{\text {mesh }}=\sum_{1}^{N} l_{\text {average }}\left(\frac{1-f_{\text {mesh }}(k)}{1-f_{\text {average }}(k)}\right)=\frac{N \times l_{\text {average }}}{1-f_{\text {average }}(k)} \times \frac{1}{N} \sum_{1}^{N}\left(1-f_{\text {mesh }}(k)\right)$

Therefore, from Equation 24 and Equation 25,

$\sum_{1}^{N} l_{\text {mesh }}=\frac{L}{1-f_{\text {average }}(k)}\left(1-f_{\text {average }}(k)\right)=L$

Consequently, when Equation 24 is satisfied, the cell voltage and the thickness of electrolyte become the real value. Next, from Equation 10, Equation 11 and Equation 12,

$I_{e}=-k \times I_{i}=\frac{k \times\left(V_{\text {cell }}-V_{\text {th }}\right)}{R_{i}}=k\left(f_{\text {average }}(k)-1\right) \times \frac{V_{\text {th }}}{R_{i}}$

For each mesh,

$I_{e}=-k \times I_{i}=k\left(f_{\text {mesh }}(k)-1\right) \times \frac{V_{t h}}{N} \times \frac{1}{r_{i}}$

Here, the ionic conductivity is constant. Thus,

$\frac{r_{i}}{l_{\text {mesh }}}=\frac{R_{i}}{N \times l_{\text {average }}}$

From Equation 29,

$\frac{1}{N \times r_{i}}=\frac{l_{\text {average }}}{R_{i} \times l_{\text {mesh }}}$

From Equation 28 and Equation 30,

$I_{e}=k\left(f_{\text {mesh }}(k)-1\right) \times \frac{l_{\text {average }} \times V_{\text {th }}}{l_{\text {mesh }} \times R_{i}}$

Considering continuity, from Equation 27 and Equation 31,

$l_{\text {mesh }}=l_{\text {average }}\left(\frac{1-f_{\text {mesh }}(k)}{1-f_{\text {average }}(k)}\right)$ 
Consequently, the cell voltage, thickness and continuity is reflected in Equation 18. Equation 24 is the only necessary condition. The electrical field (E) is expressed as,

$$
E=\frac{V_{\text {mesh }}}{l_{\text {mesh }}}=\frac{V_{t h} \times f_{\text {mesh }}(k)}{L} \times\left(\frac{1-f_{\text {average }}(k)}{1-f_{\text {mesh }}(k)}\right)
$$

The value of $\mathrm{E}$ increases with an increase in fmesh $(\mathrm{k})$. Consequently, E cannot be constant. This means that the constant field approximation cannot be justified solely by Wagner's equation and continuity.

\section{APPENDIX 2}

In this report, 500 meshes are used for the calculation from Equation 18. Here, a 30 meshes calculation example is shown. Calculating fmesh(k), Equation 34 was inserted into Equation 17.

$$
p \mathrm{O}_{2}=\frac{p \mathrm{O}_{2 \_ \text {mesh }}^{\prime}+p \mathrm{O}_{2 \_ \text {mesh }}^{\prime \prime}}{2}
$$

where $p \mathrm{O}_{2 \_ \text {mesh }}^{\prime}$ and $p \mathrm{O}_{2 \_ \text {mesh }}^{\prime \prime}$ are the oxygen pressure of the cathode and anode side of each mesh, respectively.

\begin{tabular}{|c|c|c|c|c|c|c|c|}
\hline Mesh No. & $\log (\mathrm{pO} 2)$ & fmesh (k) & Imesh & Distance from the Cathode & Vmesh & Potential & Electrical Field \\
\hline Cathode & 0 & & $(\%)$ & $(\%)$ & (Volt) & (volt) & (Volt/m) \\
\hline 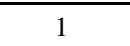 & -0.9027 & 0.999992278 & $1.12 \mathrm{E}-04$ & $1.12 \mathrm{E}-04$ & 0.039138 & 0.904079 & $1.75 \mathrm{E}+08$ \\
\hline 2 & -1.80539 & 0.999987017 & $1.88 \mathrm{E}-04$ & $3.00 \mathrm{E}-04$ & 0.039137 & 0.864941 & $1.04 \mathrm{E}+08$ \\
\hline 3 & -2.70809 & 0.99997817 & $3.16 \mathrm{E}-04$ & $6.16 \mathrm{E}-04$ & 0.039137 & 0.825804 & $6.19 \mathrm{E}+07$ \\
\hline 4 & -3.61079 & 0.999963295 & $5.32 \mathrm{E}-04$ & $1.15 \mathrm{E}-03$ & 0.039136 & 0.786667 & $3.68 \mathrm{E}+07$ \\
\hline 5 & -4.51349 & 0.999938286 & 8.94E-04 & $2.04 \mathrm{E}-03$ & 0.039135 & 0.747531 & $2.19 \mathrm{E}+07$ \\
\hline 6 & -5.41618 & 0.999896237 & $1.50 \mathrm{E}-03$ & $3.55 \mathrm{E}-03$ & 0.039134 & 0.708395 & $1.30 \mathrm{E}+07$ \\
\hline 7 & -6.31888 & 0.999825544 & $2.53 \mathrm{E}-03$ & $6.07 \mathrm{E}-03$ & 0.039131 & 0.669261 & $7.74 \mathrm{E}+06$ \\
\hline 8 & -7.22158 & 0.999706702 & $4.25 \mathrm{E}-03$ & $1.03 \mathrm{E}-02$ & 0.039126 & 0.63013 & $4.60 \mathrm{E}+06$ \\
\hline 9 & -8.12428 & 0.999506944 & $7.15 \mathrm{E}-03$ & $1.75 \mathrm{E}-02$ & 0.039119 & 0.591004 & $2.74 \mathrm{E}+06$ \\
\hline 10 & -9.02697 & 0.999171247 & $1.20 \mathrm{E}-02$ & $2.95 \mathrm{E}-02$ & 0.039105 & 0.551886 & $1.63 \mathrm{E}+06$ \\
\hline 11 & -9.92967 & 0.998607311 & $2.02 \mathrm{E}-02$ & 4.97E-02 & 0.039083 & 0.51278 & $9.68 \mathrm{E}+05$ \\
\hline 12 & -10.8324 & 0.997660535 & $3.39 \mathrm{E}-02$ & $8.36 \mathrm{E}-02$ & 0.039046 & 0.473697 & $5.76 \mathrm{E}+05$ \\
\hline 13 & -11.7351 & 0.996072654 & $5.69 \mathrm{E}-02$ & $1.40 \mathrm{E}-01$ & 0.038984 & 0.434651 & $3.42 \mathrm{E}+05$ \\
\hline 14 & -12.6378 & 0.993414135 & $9.54 \mathrm{E}-02$ & $2.36 \mathrm{E}-01$ & 0.03888 & 0.395666 & $2.04 \mathrm{E}+05$ \\
\hline 15 & -13.5405 & 0.988975915 & $1.60 \mathrm{E}-01$ & $3.96 \mathrm{E}-01$ & 0.038706 & 0.356786 & $1.21 \mathrm{E}+05$ \\
\hline 16 & -14.4432 & 0.981602166 & 2.67E-01 & $6.62 \mathrm{E}-01$ & 0.038418 & 0.31808 & $7.20 \mathrm{E}+04$ \\
\hline 17 & -15.3459 & 0.969448653 & 4.43E-01 & $1.11 \mathrm{E}+00$ & 0.037942 & 0.279662 & $4.28 \mathrm{E}+04$ \\
\hline 18 & -16.2486 & 0.949678178 & $7.29 \mathrm{E}-01$ & $1.83 \mathrm{E}+00$ & 0.037168 & 0.24172 & $2.55 \mathrm{E}+04$ \\
\hline 19 & -17.1513 & 0.918193388 & $1.19 \mathrm{E}+00$ & $3.02 \mathrm{E}+00$ & 0.035936 & 0.204552 & $1.52 \mathrm{E}+04$ \\
\hline 20 & -18.0539 & 0.869712094 & $1.89 \mathrm{E}+00$ & $4.91 \mathrm{E}+00$ & 0.034039 & 0.168616 & $9.01 \mathrm{E}+03$ \\
\hline 21 & -18.9566 & 0.798795181 & $2.92 \mathrm{E}+00$ & $7.82 \mathrm{E}+00$ & 0.031263 & 0.134577 & $5.36 \mathrm{E}+03$ \\
\hline 22 & -19.8593 & 0.702482363 & $4.31 \mathrm{E}+00$ & $1.21 \mathrm{E}+01$ & 0.027494 & 0.103314 & $3.19 \mathrm{E}+03$ \\
\hline 23 & -20.762 & 0.584072073 & $6.03 \mathrm{E}+00$ & $1.82 \mathrm{E}+01$ & 0.022859 & 0.07582 & $1.90 \mathrm{E}+03$ \\
\hline 24 & -21.6647 & 0.455090854 & $7.90 \mathrm{E}+00$ & $2.61 \mathrm{E}+01$ & 0.017811 & 0.052961 & $1.13 \mathrm{E}+03$ \\
\hline 25 & -22.5674 & 0.331866241 & $9.68 \mathrm{E}+00$ & $3.57 \mathrm{E}+01$ & 0.012989 & 0.03515 & $6.71 \mathrm{E}+02$ \\
\hline 26 & -23.4701 & 0.228043679 & $1.12 \mathrm{E}+01$ & $4.69 \mathrm{E}+01$ & 0.008925 & 0.022161 & $3.99 \mathrm{E}+02$ \\
\hline 27 & -24.3728 & 0.149436798 & $1.23 \mathrm{E}+01$ & $5.93 \mathrm{E}+01$ & 0.005849 & 0.013236 & $2.37 \mathrm{E}+02$ \\
\hline 28 & -25.2755 & 0.094605121 & $1.31 \mathrm{E}+01$ & $7.24 \mathrm{E}+01$ & 0.003703 & 0.007387 & $1.41 \mathrm{E}+02$ \\
\hline 29 & -26.1782 & 0.058508462 & $1.36 \mathrm{E}+01$ & $8.60 \mathrm{E}+01$ & 0.00229 & 0.003685 & $8.39 \mathrm{E}+01$ \\
\hline \multirow[t]{3}{*}{30} & -27.0809 & 0.035642327 & $1.40 \mathrm{E}+01$ & $1.00 \mathrm{E}+02$ & 0.001395 & 0.001395 & $4.99 \mathrm{E}+01$ \\
\hline & & 0.769995795 & & & 0.904079 & & \\
\hline & & $\begin{aligned} & \uparrow \Sigma \mathrm{f}(\mathrm{k}) / 30 \\
= & \text { faverage }(\mathrm{k})\end{aligned}$ & & & $\begin{array}{l}\uparrow \Sigma V_{\text {mesh }} \\
=V_{\text {cell }}\end{array}$ & & \\
\hline
\end{tabular}

Table 2-1. 30 Meshes Calculation Example $(k=0.1)$ 
Table 2-2. The Calculation of Iext when $R_{i}$ is $1 \mathrm{ohm}$

\begin{tabular}{|c|c|c|c|c|c|c|}
\hline $\mathbf{k}$ & Vth (Volt) & faverage $(k)$ & $\begin{array}{c}\text { Vcell }(\text { Volt }) \\
=V_{\text {th }} \times \text { faverage }(k)\end{array}$ & $\begin{array}{c}\mathbf{I i}(\mathbf{A}) \\
=\left(\mathbf{V}_{\text {th }}-\mathbf{V}_{\text {cell }}\right) / \mathbf{1}\end{array}$ & $\begin{aligned} & \mathbf{I e}(\mathbf{A}) \\
= & -\mathbf{k} \times \mathbf{I} \mathbf{i}\end{aligned}$ & $\begin{array}{l}\text { Iext (A) } \\
=\mathbf{I}+\mathbf{I} \mathbf{e}\end{array}$ \\
\hline 0.1 & 1.174135 & 0.769996 & 0.904079 & 0.270056 & -0.02701 & 0.24305 \\
\hline
\end{tabular}

\section{APPENDIX 3}

The calculated electronic current without constant field approximation matches the values predicted by Reiss' model. Theoretical explanation is given in this Appendix.

One goal of this paper is to develop a simple numerical method to solve the relevant equations in the current system without making any assumptions. Equation 16 and 17 cannot be integrated mathematically, and must be solved numerically. Using a numerical method, the analytical results from the Riess's model is verified. Riess's model is compatible with a generalized version of Wagner's equation. So the close match between the current data and Riess's model is not surprising at all. But continuity is not included in Equation 16 and 17.

The assumption of constant ionic conductivity will lead to the constant field when there is no chemical potential gradient. In appendix 1, the assumption of constant ionic conductivity is used. But Fig. 8 shows the chemical potential gradient. Therefore, the constant field approximation can not be used in this case. Riess's model is not compatible with a generalized version of Wagner's equation and continuity.

\section{REFERENCES}

Wagner C. Beitrag zur Theorie des Anlaufvorgangs. Z Phys Chem 1933; B41: 42.

[2] Rickert H. 'Electrochemistry of Solids - An Introduction' (Springer, Berlin, Heidelberg, 1982), p. 99.

[3] Zha SW, Xia CR, Meng GY. Calculation of the e.m.f. of solid oxide fuel cells. J Appl Electrochem 2001; 31: 93-8

[4] Riess I. Current-voltage relation and charge distribution in mixed ionic electronic solid conductors. J Phys Chem Solids 1986; 47; $129-38$
[5] Miyashita T. Necessity of verification of leakage currents using Sm doped Ceria electrolytes in SOFCs. J Mater Sci 2006; 41:3183-4.

[6] Lai W, Haile SM. Electrochemical impedance spectroscopy of mixed conductors under a chemical potential gradient: A case study of Pt|SDC|BSCF. Phys Chem Chem Phys 2008; 10; 865-883

[7] Lai W, Haile SM. Impedance spectroscopy as a tool for chemical and electrochemical analysis of mixed conductors: A Case Study of Ceria. J Am Ceram Soc 2005: 88(11); 2979-97. 